\title{
A Perspective of the Innovation-Diffusion Process from the Self-Organizing System
}

\author{
Toshio Mitsufuji \\ Department of Info-Media, Slebold University of Nagasaki, 822 Yoshimuta-Go, Nagayo-Cho, \\ Nagasaki-Ken, Japan 851-5086 \\ +81(95) 813-5086 \\ mitsufuji@sun.ac.jp
}

\begin{abstract}
The purpose of this paper is to examine the conventional diffuison theory and the critics against it, and to propose a conceptual model for the innovationdiffusion process into the social system. Applying the evolutionary perspective focusing on the self-organizing system, the conceptual model for the innovation-diffusion process is built. Based on the investigation, this paper argues the necessity of reconstructing the diffusion-innovation theory in terms of the self-organizing system. Especially, this paper proposes the reconsideration of the critical mass, innovator/imitator dichotomy, and the meanings of such parameters as internal and external influence factors as well as the number of the potential adopters.
\end{abstract}

\section{INTRODUCTION}

This study aims at rethinking the innovation-diffusion theory and trying to propose a conceptual model for interpreting the diffusion process in terms of the self-organizing system. The conventional innovation-diffuison theory was first integrated and established around 1960s. Since then, many diffusion studies have been performed in various fields based on it. However, partly due to the recent trends that the development of innovations is expanding at a great rate, there have appeared many phenomena that the conventional diffusion theory cannot explain appropriately. As a result, the conventional theory has been sometimes criticized from several academic fields.

The original version of this chapter was revised: The copyright line was incorrect. This has been corrected. The Erratum to this chapter is available at DOI: 10.1007/978-0-387-35404-0_19 
This paper will examine the conventional diffuison theory and the critics against it, and will propose a conceptual model for the innovationdiffusion process into the social system, assuming that it is a dynamic and self-organizing system. Based on the analysis, this paper will argue the necessity of reconstructing the diffusion-innovation theory in terms of the self-organizing system.

\section{THE CONVENTIONAL INNOVATION- DIFFUSION THEORY}

Rogers first published "Diffuison of Innovations" in 1962, which was one of the most seminal works in the innovation-diffusion research area. According to him (1995), "diffusion is the process by which an innovation is communicated through certain channels over time among the members of a social system" (p.5). Bass (1969) analyzes statistically the innovationdiffusion process of durable goods based on the Rogers' diffusion theory in the field of marketing, dividing the diffusion process into external and internal influence factors. (See also Mahajan and Peterson, 1985; Mahajan, Muller and Bass, 1990). Mansfield (1961), an economist, introduces an imitation model to analyze the innovation-diffusion process of industrial machines among industries.

In these diffusion thoughts that first appeared several decades ago, the development process of an innovation is usually divided into such phases as needs/problems, research, development, commercialization, diffusion and adoption, and consequences, occurring one by one. In addition, it is also assumed that an innovation itself does not change significantly to influence its innovation-diffusion process while it diffuses into the social system. In other words, the innovation process is implicitly considered to be independent from the diffuison process.

When these thoughts are together called a conventional innovationdiffusion theory or model, it can be pointed out that it regards technological development as a linear process. Referring to the overview of innovation in terms of R \& D activities, Kline and Rosenberg (1986) argue that "models that depict innovation as a smooth, well-behaved linear process badly misspecify the nature and direction of the causal factors at work." Furthermore, they propose the chain-linked model, in which research, invention, innovation, and production are linked mutually and various feedback loops are formed among these phases. Finally, they assert persuasively that "innovation is inherently uncertain, somewhat disorderly, made up of some of the most complex systems known, and subject to 
changes of many sorts at many different places within the innovation organization."

Williams and Edge (1996) depict the recent development of the "social shaping of the technology." In their article, they contend that the linear model "describes technologies as 'applied science', emerging through a sequential flow from basic science, through applied R\&D to commercial production and use/consumption: it conceives the cycle of inventioninnovation-diffusion as separate 'stages' in an essentially linear process" ( $p$. 847). Latour (1987), a social-shaping theorist, describes the process toward the establishment of the scientific theory and/or the technological artifacts as being quite complex and uncertain. He explains a series of innovation and/or invention processes from the beginning to the establishment in the social system, referring to the examples such as the development of work stations, the biochemical discovery and so on. Based on these studies, he argues the diffusion model as being "[s]pewed out by a few centres and laboratories, new things and beliefs are emerging, free floating through minds and hands, populating the world with replicas of themselves" (p.133). In addition, instead of the diffusion model, he proposes the translation model in which the interpretations are "given by the fact-builders of their interests and that of the people they enroll" (p.108).

Utterback (1994) argues the dynamics of innovation development, referring to the developmental phases that are classified into fluid, transitional, and specific ones. Uncertainty conditions are predominant in the fluid phase, while "market acceptance of a product innovation and the emergence of a dominant design are its hallmark" (p.96) in the transitional phase. Further, in the specific phase, the technology becomes mature and various incremental improvements take place. Tushman and Rosenkopf (1992) propose a model of technical change that is driven by sociocultural processes of variation, selection, and retention, referring to the evolutionary theory, based on empirical surveys such as cement manufacturers, the diagnostic imaging industry, and so forth. In addition, they analyze the technological change in terms of the evolution theory, and propose a cyclical model, which has four components, that is, technological discontinuities, eras of ferment, dominant designs, and eras of incremental change. Because this is a cyclical model, technological discontinuities begin after the eras of incremental change. Technological discontinuities, a dominant design, and an era of incremental change are introduced on the analogy of the variation, selection and retention within the process of the biological evolution theory, respectively. According to them, Technological substitution, design competition, and community driven technical change occur in the eras of ferment, which arise after the technological discontinuities, until a dominant design appears as the result of the selection process. (See also, for example, 
Tushman and Anderson, 1986; Anderson and Tushman, 1990; Tushman and O'Reilly, 1997.)

In economics, evolutionary economics has attracted many scholars' attention (Dosi, 1991) and several theories are proposed such as the technological trajectory (Dosi, 1982), the path dependency (David, 1985), the lock-in mechanism (Arthur, 1988) and so forth. Metcalfe (1995) argues that the economics of technology can be outlined from "two quite different perspectives, the equilibrium view and the evolutionary view " (p. 410). The characteristics of the latter are "not equilibrium and state but process and change" (p. 414). Neo classical economic theory, which treats innovations and technologies as exogenous variables from the equilibrium perspective, has been criticized for a long time.

Concerning the relationships between evolution and self-organization, Kauffman (1996), a biological evolution scholar of Santa Fe Institute, describes the evolutionary process with confidence that "much of the order in organisms may not be the result of selection at all, but of the spontaneous order of self-organized system" (p. 25). In addition, he mentions that the evolution process is composed of both selection and self-organization. Bak and Chen (1991), another scholars of Santa Fe Institute, assert that many composite systems have the characteristics of the self-organized criticality and they evolve naturally toward the critical state, in which even a very tiny event will cause the chain reactions that can affect infinite elements in the system. They still argue that some specific laws exist in the self-organizing system. In addition, Bak (1996) describes that "self-organized critical systems evolve to the complex critical state without interference from any outside agent" (p. 31).

The concept of the self-organizing system seems to be not necessarily emphasized within the framework of the innovation-diffusion theory, at least not fully developed within it. On the other hand, several studies have been conducted to analyze the technological change and innovation process, based on the concept of the self-organizing system as mentioned above. In this paper, I will try to reconstruct the innovation-diffusion process and to make some propositions in order to interpret the innovation-diffusion theory in terms of the self-organizing system.

\section{MODELING THE INNOVATION-DIFFUSION PROCESS}

Conventional innovation theories assume that innovations do not vary significantly while they diffuse into a social system. In actuality, innovations alter their aspects considerably when they diffuse into the social system. 
Various interactions that cannot be ignored exist between innovations and the social system. On the other hand, the recent development of the complexity systems theory shows that many dynamic social systems in which complex interactions exist among elements follow the theory of the self-organizing system. This paper assumes that considerable interactions exist when innovations diffuse into the social system. On this occasion, the self-organizing systems are defined as the "systems, that even when they start from an almost homogeneous or almost random state, spontaneously form large-scale patterns," following Krugman (1996, p. 3).

\subsection{Some premises for actors and factors affecting an innovation- diffusion process}

If the innovation-diffusion process shows the self-organizing pattern, there must be specific laws, as is talked by Bak and Chen (1991). In general, the social system must have different dynamic characteristics from those existing in the evolutionary process of creatures or physical/chemical phenomena. An innovation-diffusion process is a dynamic one, in which human beings take part, so that there are various states peculiar to human beings and social systems they construct. What is characteristic about the technological innovations is that many of them are embodied in the artifacts. This paper will examine the innovation-diffusion process of these artifacts put on the public consumers' market. Assuming that there are considerable interactions between an innovation and its diffusion process into a social system, this paper will make following premises.

1. Potential adopters of an innovation make their decisions whether they will implement it or not, considering both internal and external influence factors.

2. Innovation providers not only attempt to appeal to potential users in order to make the innovation diffuse into the social system, but also make an effort to enhance its efficiency and effect.

3. Various other actors and social groups take part in the innovationdiffusion process in order to promote or block the diffusion of an innovation, forming its external environment.

4. An artifact that embodies the innovation is the focal point among users, providers, and other relevant actors and social groups. Once an artifact is put on the market, it is by no means easy to change the design, so that it constitutes an idiosyncratic point within the social system and structurizes the social system. 
An innovation-diffusion model taking into account the selforganizing system

Based on the premises mentioned above, I will propose an innovationdiffusion model in terms of an evolutionary perspective taking into account the self-organization as well as the selection process. Tushman and Rosenkopf (1992) show the cyclical model of technology on the analogy of evolution theory: variation, selection, and retention. Besides, Utterback (1996) argues the appearance of the dominant design after the fluid phase. They build their cyclical models of technological change based on various empirical studies, and I will follow their classification on the innovationdiffusion process. Incidentally, while they focus on the technological cycle, I will pay a specific attention to the process of technological diffusion so that I will modify their classification some.

As the development of technologies speeds up, various innovations are continuously put on the market. Thus, for example, Basalla (1988) urges that technological development be not only continuous but also selective, forming an "evolutionary" process, the idea of which may strengthen the standpoint of a cyclical model of technology. However, it must be of important meaning to interpret the technological development as the diffusion process, because by doing so we would be able to more fully understand the relationship between the innovation and the social system in which it diffuses. In actuality, many innovations, which ordinary people have neither imagined nor believed in beforehand, have revealed themselves repeatedly and attracted a great deal of attention. Moreover, I will stress the importance of the self-organization as well as the selection process. Accordingly, referring to the cyclical model of technology, I will develop an innovation-diffusion model in terms of the evolutionary perspective taking into account the self-organizing system as follows.

1. Appearance of an innovation that overthrows the existing technological paradigm.

2. Trial and error by engineers and related organizations' staff as well as the participation of various social groups.

3. Appearance of the dominant design and passing through the irreversible phase.

4. Stabilization and fixation of the innovation in the social system.

5. Full-scale penetration of the innovation into the social system.

Next, I will explain each phase, sometimes referring to the innovationdiffusion process of Japanese word processors into the Japanese society around 1980s. I have chosen the innovation-diffusion process of Japanese word processors as the object of this analysis, because of several reasons. First of all, the implementation of Japanese word processors or, more 
generally, their functions into the Japanese society has a tremendous impact on it. Before the appearance of Japanese word processors, ordinary people thought that the usage of such devices as writing a letter sitting in front of a desktop machine was a sheer fantasy. Second, this innovation-diffusion process occurred in the rather closed social system, say, Japanese society, so that if anything it was convenient to follow and examine the process. Third, because they are consumer goods as well as office goods, we can expect that there have been various interactions between the innovation and the social system, and they have affected each other enormously.

\subsection{The appearance of an innovation that overthrows the existing technological paradigm}

In the first stage, an innovation appears that overthrows the existing technological paradigm in a social system. The word "paradigm" is defined for the time being as an exemplar serving as a technological model. The environment surrounding the existing paradigm has changed without being noticed so that the social system has exceeded the self-organized criticality (Bak and Chen, 1991) to yield an innovation.

An innovation is brought up in the social system, denying the existing technologies and/or ideas that have been regarded as natural and common. An innovation arises from those human activities as foresight, insight, intuition and so on, induced by the environment change. For example, Japanese word processors were first put on the Japanese market in 1978. Until then, even the scholars of relevant areas such as information engineering never believed that Japanese ordinary people could make use of such equipment as to write Japanese characters. Because Japanese characters are composed of ideograms as well as phonograms so that they have many characters, some scholars had thought that it was almost impossible to type Japanese languages using such keyboard as QWERTY-type. The appearance of the Japanese word processors surprised Japanese people as well as professionals to a great extent.

\subsection{Trial and error by engineers and related organizations' staff as well as the participation of various social groups}

After the appearance of an innovation, engineers or relevant professionals witnessing the innovation conduct various kind of trial and error to compete with each other. In addition to these professionals, relevant social groups such as frequent users, consumers' organizations, professional users' groups and so forth will join the innovation-diffusion process so as to interpret it. 
Pinch and Bijker (1987) call these behaviors interpretative flexibility, after examining the history of the bicycle. This may correspond with the fact that the explosion of the biological creativity took place in the Cambrian, the phenomenon of which Kauffman (1995, p.199) depicts using the analogy of the self-organization. Sometimes firms operate antennae shops to explore the consumers' trends. On the other hand, users and/or consumers in the social system communicate with each other, trying to obtain appropriate information in order to decide whether they should adopt or not. In this stage, as no one knows the optimum design, various artifacts (= products) are put on the market (Utterback, 1996). All sorts of efforts should be done so as to enroll members of the social system including engineers, relevant organizations, and various social groups and to receive much attention from members of the social system (Latour, 1987).

Conventional diffuison theories usually do not consider the modifications of the innovation while it diffuses, but take it for granted that the innovation is invariable. In actuality, the environment surrounding an artifact, in which an innovation is embodied, transforms all the time based on the technological evolutions, cultural change, alteration of the institutions, and the change of other various factors.

Bass (1969) proposes the diffusion model as follows:

$$
\mathrm{dx} / \mathrm{dt}=\mathrm{a} * \mathrm{x} *(1-\mathrm{x} / \mathrm{K})+\mathrm{b} *(\mathrm{~K}-\mathrm{x})
$$

where,

$\mathrm{x}$ : cumulative number of adopters at time $t$,

$\mathrm{K}$ : total number of potential adopters in the social system,

a: internal influence factors, and,

b: external influence factors.

According to Mahajan and Peterson (1985, pp. 15-17), internal influence factors represent horizontal channels of communication, decentralized channels of communication, unstructured, informal channels of communication, while external influence factors do vertical channels of communication, centralized channels of communication, structured channels of communication, and formal channels of communication. These parameters of $a, b$, and $K$ must change as the innovation diffuses into the social system and interact with it. From this perspective, it may be more convenient to express the Bass model as follows, adding the discontinuance factor,

$$
x_{n+1}=x_{n}+a^{*} x_{n} *\left(1-x_{n} / K\right)+b *\left(K-x_{n}\right)+c * x_{n},
$$


where,

$\mathrm{x}_{\mathrm{n}}$ : cumulative number of adopters at discrete time $\mathrm{n}$, and,

c: discontinuance ratio of the innovation.

Of course, $a, b, c$, and $\mathrm{K}$ are the functions of time $\mathrm{n}$. For example, the potential adopters of Japanese word processors were at first, say, journalists, engineers, and specialists in offices who make out contracts. However, as Japanese word processors diffuse into the Japanese society, the potential population of adopters grows, including professionals other than engineers, ordinary office workers and so forth. In addition, while Japanese word processors diffused into the Japanese society, their features changed significantly, without doubt, influencing the parameters a, b, and c. At least in the case of the Japanese word processors, the more an innovation diffused into the social system, the more their features fitted the requirement of the potential users, the number of whom expanded as the time went by.

From a standpoint of the strategic management, an innovation provider can control these parameters while enrolling potential adopters, so as to succeed in the market. From a standpoint of the technology policy, policy makers can control these parameters in order to make an innovation diffuse into the social system. However, it is not necessarily desirable to implement an innovation immediately, but "in many cases delay is economically desirable" (Metcalfe, 1995, p.483). Exactly in this point, the strategic management and technology policy must be implemented appropriately in accordance with a lapse of the innovation-diffusion process.

\subsection{Appearance of the dominant design and passing through the irreversible phase}

Under passing through the turmoil period, the social system in which an innovation has appeared becomes changing its structure. If an innovation acquires the support of potential adopters while changing its features, successfully diffusing into the social system, the innovation will reach an irreversible phase with the symmetry breaking (l). An innovation is embodied by the dominant design, which is, according to Utterback (1996), "the one that wins the allegiance of the marketplace, the one that competitors and innovators must adhere to if they hope to command significant market following." Sometimes an innovation may have changed its features completely. By the time a dominant design appears, various relevant technologies to support an innovation are improved, and reverse salients (Hughes, 1983) are dissolved. For example, video cassette recorders (VCRs), which were put on the Japanese market in 1975, did not diffuse much for a time being. At last, after the establishment of the distribution system for the 
recorded tapes of VCRs as well as the appearance of the dominant design, they began diffusing.

An innovation has altered its features, as the social system in which the innovation was thrown has changed its structure. An innovation interacts with the social system, while various artifacts that embody the innovation are selected in the process of this interaction. For example, after Japanese word processors were put on the Japanese market first in 1978, many variants appeared in the social system one after another. Finally a dominant design appeared in the process of the selection around 1985, which introduced in most cases the QWERTY-type keyboard, even though there remained a few variants concerning the layout of the keyboard. In this period, relevant engineers improved display devices, memory devices, printers, and so forth vigorously, and reverse salients were gradually dissolved. Although the price of the word processors was 6,300,000 yen (about 50,000 dollars) per copy at first, it dropped dramatically until 1985, stabilizing at about 100,000 yen (about 700 dollars) per copy since then. The social groups using Japanese word processors expanded from various specialist groups to the more generic ones such as ordinary office workers to ordinary people in the society. It can be said that the innovation is shaped not only by engineers but also by various social groups. Finally, users could make use of Japanese word processors with a certain amount of satisfaction around 1985. It can safely be said that the social system altered its structure.

The appearance of the dominant design may roughly correspond with the critical mass point in the diffusion theory, because the innovationdiffusion process takes off on a large scale after that. However, it differs from the critical mass point by definition, because it does not matter how many people in the social system adopt the innovation but what is essential is that the irreversible or self-sustaining state with symmetry breaking takes place in the social system. Quasi S-shaped diffusion curve may begin from this point, even though it lacks left and lower part of the "S" (2).

\subsection{Stabilization, fixation and full-scale penetration of the innovation into the social system}

Once an innovation has surpassed the irreversible phase, obtaining the dominant design, it becomes embedded into the social system. Some innovations diffuse explosively when the dominant designs appear ${ }^{(3)}$. An innovation achieves the stable position in the social system. The potential adopters do not care very much whether other members of the social system have adopted it or not, but pay more attentions to the efficiency and the costeffectiveness of the innovation ${ }^{(4)}$. The population of the potential adopters increases from rather the specific group to the more generic group in the 
social system. Innovation providers must follow the dominant design in order to sell their products in the market place (Utterback, 1996). They concentrate their effort on the improvement of the cost-effectiveness of the product that embodies the innovation rather than exploring the variants, in order to prevail in the market.

After the stabilization and fixation of the innovation, full-scale diffusion process occurs within the social system. Now the innovationdiffusion process enters into the closure phase (Pinch and Bijker, 1987), in which a consensus emerges and the points at issue apparently disappear. The innovative artifact becomes an ordinary one and infiltrates into the social system. The social system enters into the state in which it accepts and allows the existence of the innovation. It alters its structure from previous one, and it cannot remain effectively without the innovation. As far as Japanese word processors are concerned, after they have diffused into the Japanese society to reach about 40 per cent of the Japanese household, they are being replaced by multimedia personal computers that have the Japanese word processing function. Now, even cellular phones have the Japanese word processing function in it. People in Japan cannot work or even live their ordinary lives without devices having the Japanese word processing functions.

\section{SOME IMPLICATIONS AND CONCLUDING REMARKS}

I have proposed the innovation-diffusion model based on the evolutionary perspective, focusing on the self-organizing system. I have depicted this model referring to the actual innovation-diffusion process of Japanese word processors in the Japanese society. Based on the result of the conceptual investigation as well as the observation of an actual innovationdiffusion process, I will make some propositions in order to reconsider the innovation-diffusion theory.

First of all, the concept of "critical mass" should be reconsidered. Critical mass is defined as "the point at which enough individuals have adopted an innovation so that the innovation's further rate of adoption becomes self-sustaining " (Rogers, 1995, p. 313). The critical mass is of the social system perspective, while the dominant design is of the technology perspective. Very likely, the critical mass would take place following the appearance of the dominant design, because without that the full-scale diffusion process of the innovation would not occur. Furthermore, the formation of the critical mass will result from the interaction of the social system with the artifact not only embodying the innovation but also changing its features as it diffuses into it. At any rate, we can hardly 
determine the critical mass point due to the difficulty of the measurement of individuals' propensity toward the innovation, but we will have to be satisfied to determine the appearance of the dominant design. Some innovation-diffusion studies conducted in the 1950s and 1960s such as the hybrid corn for the US farmers (Griliches, 1957), the medical innovations in the US doctors' society (Coleman et al. 1966) focused on the innovations which some authoritative laboratories had already established. That is, the dominant design has been settled before the diffusion process begins. The model proposed here is in some sense a kind of an extended one of the conventional diffusion theory.

Secondly, we need to rethink the innovator-imitator dichotomy. Supposing that innovators would exist, they would act ardently in the second phase of this model as both engineers or members of relevant developing organizations who exert themselves to improve and enhance the innovation, and members of relevant social groups who exert themselves to interpret and shape the innovation. After the appearance of the dominant design in the social system, it is hard to think that there still exist innovators, at least it is almost meaningless to assume the existence of innovators in practice. In addition, we will need to reconsider the role of the opinion leaders, change agents, and so forth in compliance with this context.

Thirdly, on the premise that the internal influence factors (a), external influence factors (b), and the number of the potential adopters $(\mathrm{K})$ affect the innovation-diffusion process, changes in these parameters cannot be ignored as an innovation diffuses into the social system. Especially these parameters before the appearance of the dominant design will be different from those after that period. Very likely, internal influence factors before the dominant design will be larger than after that, while the external influence factors before the dominant design will be smaller than after that period. Finally, the number of the potential adopters will increase as an innovation diffuses into the social system.

Therefore, fourthly, as these parameters would be controllable, so that strategic planners or policy makers could exhibit their abilities in order to diffuse the innovation. Even if it would be very hard to estimate precisely the rate of adoption, we could manage the innovation-diffusion process on the whole. Without doubt, the strategies to be taken before the appearance of the dominant design should be different from those after that period ${ }^{(5)}$.

In this paper, I have focused on the innovation-diffusion process of a physical artifact into the consumer market, say, B to C market. However, it will be possible to expand and apply this investigation to the process innovation or IT software in the B to B market. For example, some dominant design for the business process in a firm should be established in its implementation process. Moreover, as a firm will also be able to control the 
internal and external influence factors as well as the number of potential adopters in it, a planner should construct strategies to implement the innovation.. In the same context as mentioned above, it would be clear that the fast diffusion of an innovation be not necessarily desirable.

To sum up, this paper has proposed a conceptual model to describe the innovation-diffusion process on the basis of the self-organizing system. Following the result of this investigation, it is necessary to survey empirically the applicability of the self-organizing system on the innovationdiffusion process. Consequently, the diffusion theory should be reconsidered in terms of the self-organizing system, for example, about the meanings of the critical mass, the S-shaped curve, and the dichotomy of the innovator and imitator model. In addition, even though it is hard to predict the innovationdiffusion process, we may be able to control the process so that we can and need to develop the strategic management and/or technology policy in order to implement the innovation successfully into the social system. Finally, applicability of the self-organizing system on the innovation-diffusion process of the IT products and processes should be surveyed in more detail.

\section{NOTES}

1 According to the theory of the dissipative structure (Prigogine \& Nicolos, 1989), "[t]he emergence of the concept of a space in a system in which space could not previously be perceived in an intrinsic manner is called symmetry breaking" (p.12).

2 In spite of the discontinuities between before and after the appearance of the dominant design the diffusion curve seems to be smooth. Some scholars may say that why it is smooth. There may be several reasons to interpret the apparent smoothness, as Phillips and Kim (1996) describe; that is, (1) marketing data are usually aggregated, (2) marketing events are affected by environmental and economic forces, (3) data sources are dictated by the needs of business, and, (4) marketing data sets may be biased by virtue of excluding cases.

3 Assuming that there are two products, old and new one, it may sometimes take place that the new product suddenly diffuses and obtains most part of the market share. This phenomenon is called punctuated equilibrium (Loch and Huberman, 1999; Krugman, 1996), which forms one of the self-organizing system.

4 According to Mitsufuji (2000) describing the implementation process of electronic network systems in Japanese firms in 1990s, many of them did not care very much whether other firms had adopted the systems or not, but paid more attentions to their efficacy and applicability. Certainly because they had acknowledged the electronic network systems to some degree, they did not need to care much of other firms.

5 Geroski (2000) mentions especially about the public policy on the technology innovation, comparing the models of technology diffusion, that even if it has only "a 
little window" for the innovation process, "small initial effects can have very large ultimate consequences."

\section{REFERENCES}

Anderson, Philip and Michael L. Tushman (1990), "Technical discontinuities and dominant designs: A cyclical model of technological change," Administrative Science Quarterly, Cornell University, 35, pp. 604-633.

Arthur, B. (1988), "Self-reinforcing mechanisms in economics," in Anderson, Arrow and Pines (eds.), The Economy As an Evolving Complex System, Perseus Books.

Bak, Per (1996), How Nature Works: The Science of Self-Organized Criticality, SpringerVerlag.

Bak, Per and Kan Chen (1991), "Self-organized criticality," Scientific American, pp. 26-33..

Basalla, George (1988), The Evolution of Technology, Cambridge University Press.

Bass, F. (1969), "A new product growth for model consumer durables," Management Science, 15(5), pp. 215-227.

Coleman, J. S., H. Menzel, and E. Katz (1957), "The diffusion of an innovation among physicians," Sociometry, 20, pp. 253-270.

Dosi, Giovanni (1982), "Technological paradigms and technological trajectories," Research Policy, 11, pp. 147-162.

Dosi, Giovanni (1991), "The research on innovation diffusion: An assessment," in Nakicenovic and Grubler (eds.) Diffusion of Technologies and Social Behavior, SpringerVerlag, pp. 179-208.

Geroski, P.A. (2000), "Models of technology diffusion," Research Policy, 29, pp. 603-625.

Hughes, Thomas (1987), "The evolution of large technological systems," in Bijker, Wiebe E., Thomas P. Hughes and Trevor Pinch (eds.), The Social Construction of Technological Systems, Cambridge: The MIT Press, pp. 51-82.

Griliches, Zvi (1957), "Hybrid corn: An exploration in the economics f technological change," Econometrica, 25 (4), pp. 501-523.

Karshenas, Masoud and Paul Stoneman (1995), "Technological diffusion," in Paul Stoneman (ed.), Handbook of the Economics of Innovation and Technological Change, Blackwell, pp. 265-297.

Kauffman, S. (1995), At Home In the Universe, Oxford University Press.

Kline, Stephen J. and Nathan Rosenberg (1986), "An overview of innovation," in R. Landau and N. Rosenberg (eds.), The Positive Sum Strategy, National Academy of Sciences, pp. 275-305.

Krugman, Paul, (1996), Self-Organizing Economy, Blackwell Publishing.

Larsen, Tor J. and Eugene McGuire (1998), Information Systems Innovation and Diffusion: Issues and Directions, Hershey: Idea Group Publishing.

Latour, Bruno (1987), Science in Action, Cambridge: Harvard University Press.

Leydesdorff, Loet and Peter Van Den Beselarr (eds.) (1994), Evolutionary Economics and Chaos Theory: New Directions in Technology Studies, New York: St. Martin's Press.

Loch, Christoph and Bernardo A. Huberman (1999), "A punctuated-equilibrium model of technology diffusion," Management Science, 45 (2), pp. 160-177.

Mahajan, Vijay, Eitan Muller, and Frank M. Bass (1990), "New product diffusion models in marketing: A review and directions for research," The Journal of Marketing, Vol. 14, pp. $1-26$. 
Mahajan, Vijay and Robert A. Peterson (1985), Models for Innovation Diffusion, Newbury Park: Sage Publishing.

Mansfield, E. (1961), "Technical change and the rate of imitation," Econometrica, 29(4): pp. 741-766.

Metcalfe, Stan (1995), "The economic foundations of technology policy: Equilibrium and evolutionary perspectives," in Paul Stoneman (ed.), Handbook of the Economics of Innovation and Technological change, Blackwell, pp. 409-512.

Mtsufuji, Toshio (2000), "The implementation of electronic network systems in Japanese firms," in Mehdi Khosrowpour (ed.) Challenges of Information Technology Management in the21st Century (IRMA2000), pp. 574-577.

Nicolos, Gregorie and Ilya Prigogine (1989), Exploring Complexity: An Introduction, New York: W. H. Freeman.

Phillips, Fred and Namwoon Kim (1996), "Implications of chaos research for new product forecasting," Technological Forecasting and Social Change, 53, pp. 239-261.

Pinch, Trevor and Wiebe Bijker (1987), "The social construction of facts and artifacts: Or how the sociology of science and the sociology of technology might benefit each other," in Bijker, Wiebe E., Thomas P. Hughes and Trevor Pinch (eds.), The Social Construction of Technological Systems, Cambridge: The MIT Press.

Rogers, Everett M. (1995), Diffusion of Innovations (Fourth edition), New York: The Free Press.

Tushman, Michael L. and Lori Rosenkopf (1992), "Organizational determinants of technological change: Toward a sociology of technical evolution," Research in Organizational Behavior, 14, pp. 311-347.

Tushman, Michael L. and Philip Anderson (1986), "Technical discontinuities and organizational environments," Administrative Science Quarterly, Cornell University, 31, pp. 439-465.

Tushman M. and C. O'Reilly (1997), Winning through Innovation, Boston: HBS Books.

Utterback, James M. (1994), Mastering the Dynamics of Innovation, Boston: HBS Books.

Williams, Robin and David Edge (1996), "The social shaping of technology," Research Policy, pp. 865-899. 